introductory textbook of quantitative chemical analysis arouse some interest. This American text is one such volume, even if it is a shortened version of the authors' more comprehensive text on the same subject which appeared in 1968. This fuller text is known to me to contain much useful material suitable for university and advanced college students in this country, and it is to be expected that the present shortened text should prove no less useful at a somewhat lower level of educational requirement. The necd for the adequate training of young scientists of many different disciplines in the methods of quantitative chemical analysis is becoming more and more important. A sound appreciation of the fundamentals of analytical chemistry is essential in most areas of chemical, biochemical and biological research.

Although school teaching can initiate the interested student to an existence of analytical chemistry as an important branch of chemical technology, it is really only at college or university that he can begin to see how the subject can be presented as a separate discipline within the wider sphere of chemical education. But this requires good teachers and good books, and this book is obviously one which has been written by experienced teachers with a keen sense of the importance and significance of a sound, integrated course in quantitative chemistry to most chemistry curricula.

Although the text is organized along fairly conventional lines (and in an introductory text this is rather hard to avoid) there are, nevertheless, several noteworthy features which make it a worthwhile and an out of the ordinary book. It covers an unusually wide field; discussions of methods of analysis include optical and electrochemical methods and the main techniques of chemical separation along with the more commonly encountered gravimetric and titrimetric methods. Indeed, no attempt is made to classify these methods into classical chemical and instrumental methods, but rather to present them as part of a much broader and flexible structure with which analytical chemistry is now identified.

It is difficult to single out particularly well-presented sections, but those on gravimetry, compleximetry and oxidation-reduction methods show unusual depth of treatment. Perhaps more could have been made of the concept of formal potential in the redox section, particularly as the concept of formality is so well explained in earlier pages of the book and indeed is used extensively to express concentrations. Details of twenty-seven experiments covering most of the range of the theoretical discourses in the book are given, and although these are not exhaustive, indications of others are given in the useful collections of problems set at the end of each chapter. This is an unusually good book which would handsomely repay study by most teachers involved in introductory courses of analytical chemistry. Its adoption as a general textbook in such courses could certainly prove beneficial to students and indeed would go far to propagate a more balanced view of the purpose of quantitative chemical analysis among our young scientists and technologists.

Wilitiam I. StTEPhen

\section{CHEMISTRY OF GERMANIUM}

\section{The Chemistry of Germanium}

By F. Glockling. Pp. viii +234. (Academic Press: London and New York, February 1969.) 75s; $\$ 11$.

THE chemistry of germanium was relatively little studied until recently. As Professor Glockling suggests, this was partly because of the comparatively high cost of germanium, and partly because of the fact that its chemistry generally falls so clearly between that of silicon and tin that little of real novelty usually emerges from detailed experimental studies. Principally because of the semiconductor uses of germanium, the metal and its com- pounds have become less costly in recent years, and this, coupled with the fact that some groups of workers are, in return for the occasional surprise, content to reproduce with germanium results well established for silicon, has led to an upsurge of work on germanium compounds. Thus Annual Surveys of Organometallic Chemistry for 1967 lists 147 referenecs to work on organogermanium compounds compared with 865 and 324 to work on organosilicon and organotin compounds respectively.

The publishers say that the book is "the first monograph to cover all aspects of the chemistry of germanium, and includes all the significant advances reported in the literature in recent years". It is a long way from mecting that description, which would probably be disowned by the author; his preface indicates that the monograph is designed partly for the general chemical reader but is also meant to include sufficient detail to provide a useful source of reference for specialist rescarch workers. The apparently wide coverage of the book is illusory, for while accounts of the properties of the metal, its alloys, and its inorganic chemistry are included, they occupy only 30 pages compared with the 140 pages (excluding references) devoted to organogermanium compounds. Again, even within the section on organogermanium compounds the treatment is highly selective; thus of the 140 pages, 52 are, rather disproportionately, concerned with compounds in which the germanium is bonded to a metal. (It should be said, however, that this section, dealing as it does with a field to which the author has made important experimontal contributions, is one of the best parts of the book. Another good section, again on a topic to which the author has made major contributions, deals with the mass spectra of organogermanium compounds.)

Unfortunately, the book cannot be recommended without reservations either to the general reader or to the specialist. For the general reader, there is insufficient classification and rationalization of the facts presented; for example, on page 82 , the sentence "Trifluoroacetic acid will cleave one phenyl group from tetraphenylgermane" appears as part of a paragraph on cleavage of allyl-germanium bonds by mercuric chloride, and thus seems to describe an isolated and possibly mysterious reaction, whereas the reaction is, in fact, a simple example of acidolysis of aryl-germanium bonds which is discussed some paragraphs earlier. For the specialist reader, the treatment of some important topics is inadequate; for example, only two pages are devoted to optical resolution of germanium compounds and the stereochemistry of substitution at germanium, and while Brook and Peddle's important resolution of the methyl-1-naphthylphenylgermanium compounds in 1963 is described, the slightly earlier resolution of ethyl-l-naphthylphenylgermanium compounds is not mentioned, and neither is the reported resolution of ethylisopropylphenylgermanium compounds in 1931. The specialist will also find that discussion of reaction mechanisms is eursory and occasionally inaccurate.

This book will be useful in spite of defects. Parts of it are good, but, more important, it is the only extensive account of organogermanium compounds in the English language, and as such will serve to provide useful leads into the original literature through its 800 or so references. It is well produced, and in terms of costs per page represents good value these days for a specialist monograph.

C. EABORN

\section{ASPECTS OF ELECTROCHEMISTRY}

\section{The Electrochemistry of Oxygen}

By James P. Hoare. Pp. xiv +423 . (Interscience (Wiley): New York and London, December 1968.) $182 s$.

MUCH of this book fulfils well the author's declared aim to provide a source of information and stimulation to 